Polymer Journal, Vol. 3, No. 1, pp 12-20 (1972)

\title{
Asymmetric Hydroboration of Diene Polymers
}

\author{
Hidemasa Yamaguchi, Koji Azuma, and Yuji Minoura \\ Department of Applied Chemistry, Faculty of Engineering, \\ Osaka City University, Sugimoto-cho, Sumiyoshi-ku, \\ Osaka, Japan.
}

(Received January 27, 1971)

\begin{abstract}
Asymmetric hydroboration of cis- and trans-1,4-polyisoprene was carried out using optically active triisopinocampheyldiborane and optically active polymers were obtained. In the case of the hydroboration of cis-1,4-polyisoprene, the use of dextrorotatory $\alpha$-pinene $\left([\alpha]_{\mathrm{D}}+14.9^{\circ}\right)$, yielded the laevorotatory polymer $\left([\alpha]_{\mathrm{D}}-2.3^{\circ}\right)$ having a 98 per cent hydroxyl group content. On the contrary, the use of laevorotatory $\alpha$ pinene $\left([\alpha]_{\mathrm{D}}-26.6^{\circ}\right.$ and $\left.-28.6^{\circ}\right)$ yielded the dextrorotatory polymers $\left([\alpha]_{\mathrm{D}}+2.4 \sim 3.6^{\circ}\right)$ having a 85-100 per cent hydroxyl group content. The absolute values of $[\alpha]_{D}$ for the polymers were increased with the increase in hydroxyl group content and the absolute value of $[\alpha]_{D}$ of $\alpha$-pinene used. The optically rotatory dispersion curves were found to fit the simple Drude equation and the $\lambda_{\mathrm{c}}$ value of the polymers was about $164 \mathrm{~m} \mu$. The $\lambda_{c}$ value suggested that the chromophore which caused optical activity was - $\mathrm{OH}$ group.

The hydroboration of trans-1,4-polyisoprene was also carried out and optically active polymers $\left([\alpha]_{\mathrm{D}}+0.6-1.2^{\circ}\right)$ having a $90-100$ per cent hydroxyl group content were obtained using $\alpha$-pinene $\left([\alpha]_{\mathrm{D}}-28.6^{\circ}\right)$. Furthermore, the asymmetric hydroboration of cis-polybutadiene, butadiene-styrene and random butadiene-acrylonitrile copolymers was carried out, but these hydroxylated polymers had no optical activity. The hydroxylated butadiene-acrylonitrile alternating copolymer showed optical activity. KEY WORDS Optical Rotatory Dispersion / Optically Active Polymer / Asymmetric Hydroboration / Hydroboration / Polymer Reaction / Diene Polymer / Polyisoprene / Butadiene Acrylonitrile Copolymer / Butadiene-Styrene Copolymer / Triisopinocampheyldiborane /
\end{abstract}

Brown, et al., ${ }^{1}$ reported in 1961, for the first time, the asymmetric hydroboration of some olefines using diisopinocampheylborane(DIB). cis-2-Butene reacted with the reagents from $\alpha$ pinene, $[\alpha]_{\mathrm{D}}+47.6^{\circ}$, to produce an organoborane, which was oxidized with alkaline hydrogen peroxide to yield 2-butanol $[\alpha]_{\mathrm{D}}-11.8^{\circ}$ (87 per cent optical purity). ${ }^{2}$ Similarly, cis-3-hexene was converted to 3 -hexanol $[\alpha]_{\mathrm{D}}-6.5^{\circ}$ (91 per cent optical purity).

The results established that the boron atom at the asymmetric center, $\mathrm{R}_{1} \mathrm{R}_{2} \mathrm{C}^{*} \mathrm{HB}-$, was capable of maintaining asymmetry without significant racemization over a period of several hours. The unusually high optical purities realized in this asymmetric hydroboration and the fact that the organoboranes may be converted into other derivatives with retention of configuration promised to be a useful approach to optically active derivatives.

The study on the hydroboration of the diene polymers such as polybutadiene and polyisoprene to produce the polymers having an hydroxyl group was carried out by one of the authors. ${ }^{3}$

In this paper, to synthesize optically active polymers from optically inactive polymer by polymer reaction, the asymmetric hydroboration of cis- and trans-polyisoprene was carried out using triisopinocampheyldiborane(TIDB). The hydroxylated polymers obtained were optically active. The specific rotation of the hydroxylated cis-1,4-polyisoprene was higher than that of the hydroxylated trans one.

The rotatory dispersion curves of the hydroxylated cis-polymers were found to fit the simple Drude equation and an average $\lambda_{c}$ value of 164 $\mathrm{m} \mu$ was obtained. The $\lambda_{\mathrm{c}}$ value suggested that the chromophore which caused optical activity 
Asymmetric Hydroboration of Diene Polymers

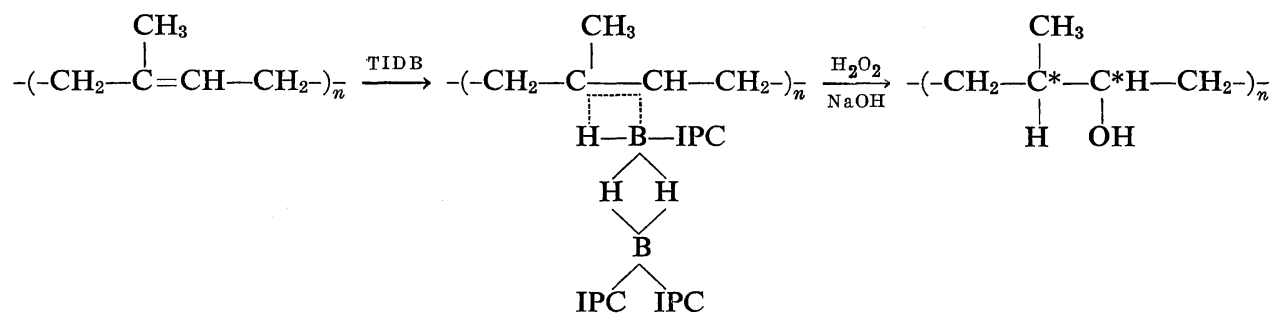

IPC, (-)-isopinocampheyl group

was the hydroxyl group.

Furthermore, the asymmetric hydroboration of cis-polybutadiene and several butadiene-styrene copolymers was attempted, but the hydroxylated polymers had no optically activity. However, the asymmetric hydroxylated butadiene-acrylonitrile alternating copolymer gave optical activity.

\section{EXPERIMENTAL}

\section{Materials}

Sodium boron hydride $\left(\mathrm{NaBH}_{4}\right)$ wás supplied by
Metal Hydride Inc. Commercially supplied boron trifluoride etherate $\left(\mathrm{BF}_{3} \mathrm{OEt}_{2}\right)$ was distilled in an atmosphere of nitrogen (bp $126.5^{\circ} \mathrm{C}$ ). Di(ethylene glycol) dimethyl ether was prepared from methyl bromide and the alcoholate which was made from sodium metal and di(ethylene glycol) monomethyl ether. It was distilled over lithium aluminum hydride at a reduced pressured before use $[b p$ $\left.84-85^{\circ} \mathrm{C}(27 \mathrm{~mm})\right] . \quad \alpha$-Pinene was steam distilled and was purified by distillation at a reduced pressure [bp $\left.51-52^{\circ} \mathrm{C}(20 \mathrm{~mm})\right]$. The specific rotations of the used $\alpha$-pinene were $+14.9,-26.6$,

Table I. Characterization of diene polymers ${ }^{\mathrm{a}}$

(a) polyisoprene and polybutadiene

\begin{tabular}{lccccc}
\hline & {$[\eta]_{30}^{\mathrm{THF}}$} & $\begin{array}{c}\text { cis-1,4, } \\
(\%)\end{array}$ & $\begin{array}{c}\text { trans-1,4, } \\
(\%)\end{array}$ & $\begin{array}{c}\text { trans-1,2, } \\
(\%)\end{array}$ & $\begin{array}{c}\text { trans-3,4, } \\
(\%)\end{array}$ \\
\hline cis-Polyisoprene & 3.31 & 92 & 3 & - & 5 \\
trans-Polyisoprene & 1.37 & 3 & 95 & - & 2 \\
cis-Butadiene & 2.70 & 92 & 3 & 5 & -
\end{tabular}

(b) butadiene-styrene copolymer

\begin{tabular}{lcccccc}
\hline \multirow{2}{*}{$\begin{array}{c}\text { butadiene-styrene } \\
\text { copolymer }\end{array}$} & {$[\eta]_{30}^{\mathrm{THF}}$} & \multirow{2}{*}{$\begin{array}{c}\mathrm{Bu} / \mathrm{St}, \\
\mathrm{mol} \%\end{array}$} & & \multicolumn{4}{c}{ Probability of sequence } \\
\cline { 5 - 7 } & & & $f_{\mathrm{Bu}-\mathrm{Bu}}$ & $f_{\mathrm{Bu}-\mathrm{St}}$ & $f_{\mathrm{St}-\mathrm{St}}$ & $F_{\mathrm{St}-\mathrm{Bu}-\mathrm{St}}$ \\
\hline Solprene 1205F & 1.03 & $85 / 15$ & 0.52 & 0.41 & 0.07 & 0.08 \\
Buna Hüls & 1.54 & $68 / 32$ & 0.11 & 0.45 & 0.44 & 0.09 \\
Hycar 2007J & 0.54 & $25 / 75$ & 0.02 & 0.26 & 0.72 & 0.04 \\
\hline
\end{tabular}

(c) butadiene-acrylonitrile copolymer

\begin{tabular}{lcccccc}
\hline \multirow{2}{*}{$\begin{array}{c}\text { Butadiene-acrylonitrile } \\
\text { copolymer }\end{array}$} & {$[\eta]_{30}^{\mathrm{THF}}$} & \multirow{2}{*}{$\begin{array}{c}\mathrm{Bu} / \mathrm{AN}, \\
\text { mol } \%\end{array}$} & & \multicolumn{3}{c}{ Probability of sequence } \\
\cline { 5 - 7 } & 1.04 & $51 / 49$ & 0.03 & 0.95 & 0.02 & 0.46 \\
\hline Alternating & & & & & & \\
Random & 1.65 & $66 / 34$ & 0.43 & 0.57 & 0.00 & 0.16 \\
\hline
\end{tabular}

a The microstructure was determined with infrared spectrum and the probability of sequence was calculated from $r_{1}$ and $r_{2}$ values.

b $[\eta]_{30}^{\text {DMF }} 1.55$. 
and $-28.6^{\circ}\left(\right.$ lit., ${ }^{4}[\alpha]_{\mathrm{D}}+48.3^{\circ}$ and $\left.-47.2^{\circ}\right)$.

Polyisoprene, polybutadiene, butadiene-styrene copolymer and butadiene-acrylonitrile copolymer (random and alternating ${ }^{5}$ ) were purified by precipitation from a benzene solution with methanol.

The value of $[\eta]$, micro structure, probability of sequence, and composition of these polymers are shown in Table $\mathbf{I}$.

Tetrahydrofuran(THF) and other solvents were purified by the usual method.

Preparation of a THF Solution of Diborane

A THF solution of diborane was prepared by Brown's method. ${ }^{6}$ In a three-necked flask equipped with a thermometer, condenser, and a pressure equalizing funnel, was placed $50 \mathrm{~g}(0.13 \mathrm{~mol})$ of $\mathrm{NaBH}_{4}$ and $50 \mathrm{~m} l$ of a di(ethylene glycol) dimethyl ether. The flask was immersed in an ice bath. $\mathrm{BF}_{3} \mathrm{OEt}_{2}(33 \mathrm{ml}, 0.26 \mathrm{~mol})$ was added dropwise to the solution and was well-stirred by a magnetic stirrer. The diborane gas produced was led with nitrogen gas and absorbed into $100 \mathrm{ml}$ of THF cooled at $0^{\circ} \mathrm{C}$. The concentration of the THF solution of diborane obtained was determined ${ }^{6}$ with measurement of the volume of hydrogen gas using a gas bulete.

Preparation of Triisopinocampheyldiborane $(T I D B)^{7}$

In a three-necked flask, equipped with a thermometer, condenser, and a pressure equalizing funnel was placed a THF solution of diborane $20 \mathrm{~m} l(0.02 \mathrm{~mol})$. The flask was immersed in an ice bath. $\alpha$-Pinene $9.5 \mathrm{~m} l(0.06 \mathrm{~mol})$ was added dropwise to a well-stirred solution. Triisopinocampheyldiborane(TIDB) precipitated partially during $\alpha$-pinene addition. The reagent was maintained for an additional $3 \mathrm{hr}$ at $0^{\circ} \mathrm{C}$ prior to use.

\section{Asymmetric Hydroboration}

In a three-necked flask, equipped with a thermometer, condenser, and a pressure equalizing funnel was placed a THF solution $(150 \mathrm{ml})$ of $1.0 \mathrm{~g}$ of polymer. A THF solution of TIDB was added to the well-stirred polymer solution under magnetic stirring. The reaction was carried out in an atmosphere of nitrogen at $0^{\circ} \mathrm{C}$ over a period of $5 \mathrm{~min}-5 \mathrm{hr}$. The reaction mixture was oxidized with alkaline-hydrogen peroxide $(10 \mathrm{~m} l$ of $3-N$ aqueous sodium hydroxide and $10 \mathrm{~m} l$ of 30 per cent hydrogen peroxide). The reaction mix- ture was precipitated into water and evaporated to remove THF. The obtained polymer was purified by precipitation from the THF solution with diethyl ether. The precipitation was carried out until the specific rotation of the polymer showed a constant value.

\section{Measurements}

The D-line optical rotation and optical rotatory dispersion were measured with a Shimadzu model QV-50 polarimeter equipped with xenon source.

The intrinsic viscosity of polymer was measured in THF at $30 \pm 0.1^{\circ} \mathrm{C}$ with an Ubelohde's viscometer.

The infrared spectra of polymers were measured with the use of film on a $\mathrm{NaCl}$ plate.

\section{RESULTS AND DISCUSSION}

\section{Asymmetric Hydroboration of cis- and trans-Poly-} isoprene

The asymmetric hydroboration of cis- and transpolyisoprene was carried out in THF at $0^{\circ} \mathrm{C}$ (Tables II and III). During the reaction, the reaction mixture remained homogeneous. It was different from the previous result; ${ }^{3}$ in the case of hydroboration of diene polymers with diborane, the gelation of the reaction mixture occurred as soon as a THF solution of diborane was added to the polymer solution but it became homogeneous after oxidizing with alkaline hydrogen peroxide. In this paper the hydroboration of polyisoprene was carried out by TIDB instead of diborane. It is evident that the gel formation of the reaction mixture does not occur because a molecule of TIDB reacts with only one $\mathrm{C}=\mathrm{C}$ double bond of the polymer and does not make the polymer-polymer linkage.

After several precipitations, a portion of the obtained polymer turned out insoluble, but THF soluble polymer was obtained. The gelation of the obtained polymer seemed to be caused by the residual impurity (trace organoboron compounds) in the obtained polymer. In the present paper, the precipitation was carried out in air. Thus the organoboron compounds remaining in the hydroxylated polymers were reacted with oxygen to give radicals during the precipitation. Welch ${ }^{8}$ and other authors ${ }^{9,10}$ reported the autoxidation of alkylboron compounds. Generally alkylboron compounds react with oxygen and readily produce: 
Asymmetric Hydroboration of Diene Polymers

Table II. Asymmetric hydroboration a of cis-1,4-polyisoprene with triisopinocampheyldiborane

\begin{tabular}{|c|c|c|c|c|c|c|}
\hline \multirow{2}{*}{$\begin{array}{l}\text { Run } \\
\text { no. }\end{array}$} & \multirow{2}{*}{$\begin{array}{l}\text { Molar ratio } \\
\text { TIDE/cis-1,4- } \\
\text { polyisoprene }\end{array}$} & \multirow{2}{*}{$\begin{array}{c}{[\alpha]_{D^{b}} \text { of used }} \\
\alpha \text {-pinene, }\left(^{\circ}\right)\end{array}$} & \multicolumn{4}{|c|}{ Hydroxylated polymer } \\
\hline & & & {$[\alpha]_{D}{ }^{c},\left(^{\circ}\right)$} & {$[\eta]^{\mathrm{d}}$} & $-\mathrm{OH}$ content, ${ }_{\%}^{e}$ & $\begin{array}{l}\text { Amount } \\
\text { of gel }\end{array}$ \\
\hline 1 & 1.4 & +14.9 & -2.3 & 0.256 & 98 & small \\
\hline 2 & 1.4 & -26.6 & +3.6 & 0.374 & 100 & small \\
\hline 3 & 1.4 & -28.6 & +2.4 & 0.359 & 92 & small \\
\hline 4 & 1.0 & -28.6 & +2.9 & 0.374 & 85 & medium \\
\hline 5 & 0.6 & -28.6 & - & - & - & large $^{f}$ \\
\hline 6 & 0.4 & -28.6 & - & - & - & largef \\
\hline
\end{tabular}

a The hydroboration was carried out for $3 \mathrm{hr}$ at $0^{\circ} \mathrm{C}$ in THF.

b Measured at $25^{\circ} \mathrm{C}$ (neat, $l=0.1$ ).

c Measured in THF at $25^{\circ} \mathrm{C}(C=1.0, l=1.0)$.

d Measured in THF at $30^{\circ} \mathrm{C}$.

- Calculated from $\mathrm{C} \%$ by elementary analysis.

\& THF soluble polymer was not obtained.

Table III. Asymmetric hydroborationa of trans-1,4-polyisoprene with triisopinocampheyldiborane

\begin{tabular}{|c|c|c|c|c|c|c|}
\hline \multirow{2}{*}{$\begin{array}{l}\text { Run } \\
\text { no. }\end{array}$} & \multirow{2}{*}{$\begin{array}{l}\text { Molar ratio, } \\
\text { TIDB/trans-1,4- } \\
\text { polyisoprene }\end{array}$} & \multirow{2}{*}{$\begin{array}{c}{[\alpha]_{D^{b}} \text { of used }} \\
\alpha \text {-pinene, }\left(^{\circ}\right)\end{array}$} & \multicolumn{4}{|c|}{ Hydroxylated polymer } \\
\hline & & & {$[\alpha]_{\mathrm{D}}^{\mathrm{c}},\left(^{\circ}\right)$} & {$[\eta]^{\mathrm{d}}$} & $-\mathrm{OH}$ content, & $\begin{array}{c}\text { Amount } \\
\text { of gel }\end{array}$ \\
\hline $10^{\mathrm{f}}$ & 1.4 & -28.6 & +1.2 & 0.280 & 90 & small \\
\hline 11 & 0.9 & -28.6 & +0.6 & 0.435 & 85 & medium \\
\hline 12 & 0.7 & -28.6 & - & - & - & largeg \\
\hline
\end{tabular}

a The hydroboration was carried out for $3 \mathrm{hr}$ at $0^{\circ} \mathrm{C}$ in THF.

b Measured at $25^{\circ} \mathrm{C}$ (neat, $l=0.1$ ).

c Measured in THF at $25^{\circ} \mathrm{C}(C=1.0, l=1.0)$.

d Measured in THF at $30^{\circ} \mathrm{C}$.

- Calculated from $\mathrm{C} \%$ by elementary analysis.

f The hydroboration was carried out for $1 \mathrm{hr}$ at $0^{\circ} \mathrm{C}$ in THF.

g THF soluble polymer was not obtained.

peroxide to yield free radicals.

$$
\begin{aligned}
& \mathrm{R}_{3} \mathrm{~B}+\mathrm{O}_{2} \quad \longrightarrow \mathrm{R}_{2} \mathrm{~B}(\mathrm{OOR}) \\
& \mathrm{R}_{3} \mathrm{~B}+\mathrm{R}_{2} \mathrm{~B}(\mathrm{OOR}) \longrightarrow \mathrm{R}_{2} \mathrm{BOR}+\mathrm{R} \cdot+\mathrm{R}_{3} \mathrm{BO} .
\end{aligned}
$$

As shown in Tables II and III, THF soluble polymers were obtained only on the condition of the hydroboration in which the molar ratio of TIDB/polyisoprene was more than unity. The carbon-carbon double bond was converted to the allyl radical by the elimination of hydroxyl radical, and thus the gelation occurred.

The THF soluble polymers had the hydroxyl group content of $80-100$ percent and were not already rubber-like materials. As shown in Figure
1, the infrared spectrum for the THF soluble polymer gave the absorption band at $3400 \mathrm{~cm}^{-1}$ due to the associated hydroxyl group and did not give the absorption band at $1670 \mathrm{~cm}^{-1}$ due to the carbon-carbon double bond. The newly induced absorption band at $1700 \mathrm{~cm}^{-1}$ was due to the carbonyl group which was produced by the oxidation of polyisoprene.

\section{Optical Behavior of Hydroxylated Polyisoprene}

The obtained polymers by oxidation after the asymmetric hydroboration of cis-polyisoprene had positive optical rotation (Table II). The hydroxylated polymers were purified by precipitation until the specific rotation showed a constant 


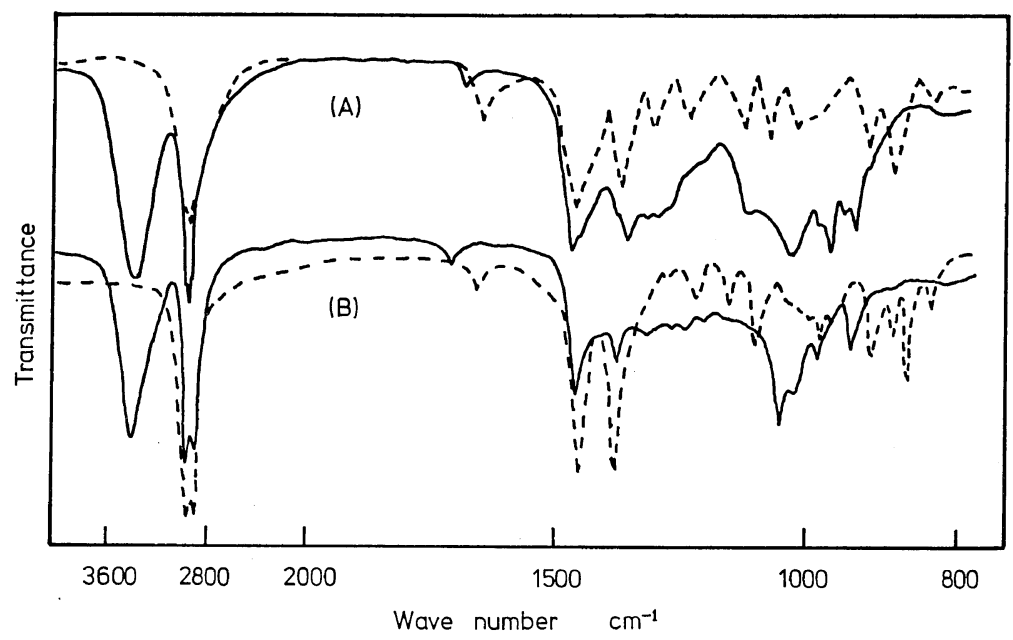

Figure 1. Infrared spectra of (A) cis-1,4-polyisoprene (----); hydroxylated cis-polyisoprene $(-)$ and (B) trans-1,4-polyisoprene (----); hydroxylated trans-1,4-polyisoprene $(-)$.

value. It is thought that the optical rotation was not caused by the impurity. It is also evident from the result that the optical rotations of hydroxylated polybutadiene, butadiene-styrene and butadiene-acrylonitrile copolymers were not detectable $\left([\alpha]_{\mathrm{D}} 0\right)$ as described later. The optical rotatory dispersion curves for these polymers are shown in Figure 2. The curves were found to fit the simple Drude equation. The average value of $\lambda_{c}$ for the polymers was about $164 \mathrm{~m} \mu$. On the other hand, the $\lambda_{\mathrm{c}}$ for pinocampheol was $174 \mathrm{~m} \mu$ and that for $\alpha$-pinene was $124 \mathrm{~m} \mu$. It would seem that the chromophore which cause optical activity for the polymer is the hydroxyl group.

In the case of the hydroboration of cis-polyisoprene, the use of dextrorotatory $\alpha$-pinene $\left([\alpha]_{\mathrm{D}}\right.$ $\left.+14.9^{\circ}\right)$, yielded the laevorotatory polymer $\left([\alpha]_{D}\right.$ $\left.-2.3^{\circ}\right)$ having a $98-\%$ hydroxyl group content. On the contrary, the use of laevorotatory $\alpha$ pinene $\left([\alpha]_{D}-26.6\right.$ and $\left.-28.6^{\circ}\right)$ yielded the dextrorotatory polymers $\left([\alpha]_{\mathrm{D}}+2.4-3.6^{\circ}\right)$ having a 85-100 per cent hydroxyl group content. The specific rotations of hydroxylated cis-polyisoprene increased with increase in the $-\mathrm{OH}$ content (hydroxylated carbon-carbon double bond), which was determined from the value of the carbon percent obtained from the elements analysis. A similar result was reported by Brown, et al., ${ }^{2}$ on

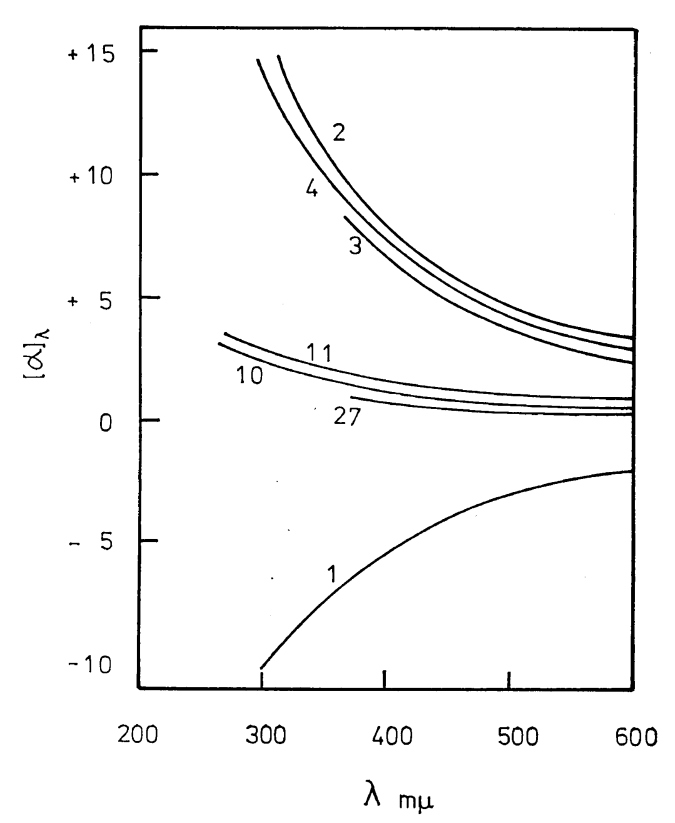

Figure 2. Optical rotatory dispersions of hydroxylated cis- and trans-1,4-polyisoprene: run no. 1, 2, 3, and 4 (Table II); run no. 10 and 11 (Table III); run no. 27 (Table IV).

the asymmetric hydroboration of low-molecularweight olefines. For example, cis-2-butene was converted to dextrorotatory 2-butanol $\left([\alpha]_{\mathrm{D}}\right.$ $\left.+11.7^{\circ}\right)$ using laevorotatory $\alpha$-pinene $\left([\alpha]_{\mathrm{D}}\right.$ 
$-47.9^{\circ}$ ) but it was converted to laevorotatory 2-butanol $\left([\alpha]_{\mathrm{D}}-11.8^{\circ}\right)$ using dextrorotatory $\alpha$ pinene $\left([\alpha]_{\mathrm{D}}+47.6^{\circ}\right)$.

The relationship between the absolute value of the specific rotation for the polymer obtained and that for used $\alpha$-pinene is shown in Figure 3. The value of specific rotation was calculated as that of the hydroxylated polymer having 100 per cent hydroxyl group content. The absolute values of specific rotation for the polymers increased with an increase in that for $\alpha$-pinene. It is confirmed from the above result that the isopinocampheyl group of TIDB is necessary for the asymmetric induction and that the optical activity of hydroxylated polymer is caused by the configuration of the used $\alpha$-pinene.

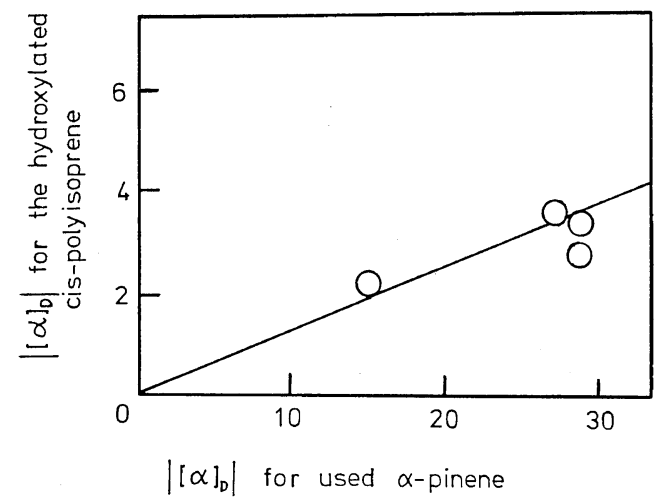

Figure 3. Relationship between the specific rotation of used $\alpha$-pinene and the absolute values of the specific rotation of hydroxylated cis-1,4-polyisoprene. (The values of the specific rotation were calculated as that of the hydroxylated polymers having 100 per cent hydroxyl group content.)

Generally, the cis addition of the boron-hydrogen bond to a double bond has been interpreted in terms of a four-center transition state. The formation of such a highly rigid transition state should be strongly influenced by steric factors of both the reagent and the polymer. According to the theory of Brown, et al., ${ }^{11}$ in the case of the hydroboration ${ }^{7}$ of cis-compounds with diisopinocampheylborane(DIB) and triisopinocampheyldiborane(TIDB), the hydroboration of polyisoprene with TIDB prepared from (-)$\alpha$-pinene can be represented by two possible transition states, I and II as follows:

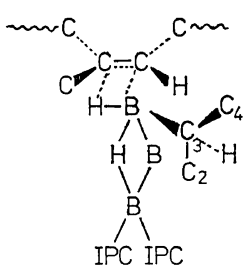

I

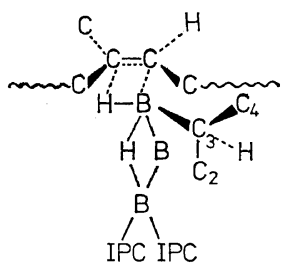

II
IPC, (-)-isopinocampheyl group

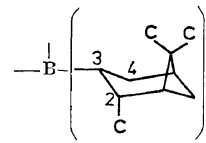

It is anticipated that the preferred transition state would be that in which the methyl group of polyisoprene is positioned away from the bulky methylene group of the isopinocampheyl group in TIDB. It is evident that the alternative transition state II will be less favorable sterically.

In the case of asymmetric hydroboration ${ }^{7}$ with DIB and TIDB, the cis addition of the boronhydrogen bond to a double bond occurs only from one of two directions (upward from $\mathrm{C}=\mathrm{C}$ and downward from $\mathrm{C}=\mathrm{C}$ ). Thus even a compound such as $\mathrm{C}-\mathrm{C}=\mathrm{C}-\mathrm{C}$ was hydroborated to obtain optically active carbinol.

The results that the difference of the sign of specific rotations of the cis-polyisoprene hydroxylated by TIDB prepared from (-)- $\alpha$-pinene and (+)-one suggest not only that the former TIDB attacks carbon-carbon double bonds from one of two directions but also that the latter TIDB does the same from the opposite directions.

The polymer obtained by oxidation after the asymmetric hydroboration of trans-polyisoprene had positive optical rotations as well as those of the polymers obtained by the hydroboration of cis-polyisoprene. The result and the reaction conditions are shown in Table III. The optical rotatory dispersion curves for these are shown in Figure 2. These curves were positive and were found not to fit the simple Drude equation. The specific rotations and the magnitude of the rotatory dispersion curves for the hydroxylated trans-polyisoprene were fairly smaller than those for the hydroxylated cis-polyisoprene.

It is already well known ${ }^{7}$ that the hydroboration of cis-olefins with optically active DIB produces alcohols in highly optical purity. The 
corresponding reactions of the reagents with trans or hinder olefins are slow, proceeding only with the displacement of $\alpha$-pinene from the reagent, and the oxidized products exhibit much lower optical activities. For example, the hydroboration of cis-butene produced (+)-2-butanol of 86-87 per cent optical purity. ${ }^{2}$ In contrast, the reaction of trans-2-butene produced (-)-2-butanol of 13 per cent optical purity. ${ }^{11}$ Similarly, 3methylcyclopentabol, cis-derivatives of 45 per cent optical purity ${ }^{11}$ and trans one of 3 per cent of optical purity. ${ }^{11}$

Although polyisoprene is tri-substituted olefin, there is no steric difference between the transition state of the hydroboration of cis-polyisoprene and that of trans-polyisoprene. Thus it is thought the fact that the specific rotation of the hydroxylated cis-polymer is higher than that of the trans one is not caused by the difference between the asymmetric inducing efficiency of the hydroboration of cis-polyisoprene and that of trans one, but is caused by the difference of the configuration of hydroxylated cis- and trans-polyisoprene. Two asymmetric carbon atoms (i.e., $\mathrm{CH}_{3} \quad \mathrm{H}$

$-{ }^{\prime}{ }^{*}-$ and $-\stackrel{C}{C}^{*}-$ ) are newly induced by the hy$\mathrm{H} \quad \mathrm{OH}$

droboration of 1,4-polyisoprene with TIDB. In the case of the hydroboration of cis-polyisoprene, the configuration of the former type asymmetric $\mathrm{H}$

carbon atom $\left(-\stackrel{1}{ }^{*}-\right)$ is the same as one of the $\mathrm{OH}$ $\mathrm{H}$

latter type asymmetric carcon atom $-\stackrel{C}{C}^{*}-$ of the hydroxylated trans-polyisoprene. On the other hand, the configuration of the $-\mathrm{C}^{*}$ - type asymmetric carbon atom has the opposite configuration compared with that of the $\left(-\mathrm{C}^{*}-\right)$ type for hydroH

xylated trans-polyisoprene.

It is thought that in the case of hydroxylated cis-polymer, two asymmetric carbon atoms enhanced its optical rotation but the asymmetric carbon atoms of the hydroxylated trans-polymer<smiles>CCCC(O)C(C)CC</smiles>

hydroxylated cis-polyisoprene<smiles>CCCC(O)C(C)CC</smiles>

hydroxylated trans-polyisoprene cancelled it. Thus the former has higher optical rotatory power than the latter.

Asymmetric Hydroboration of Polybutadiene and Butadiene-Styrene Copolymers

The asymmetric hydroborations of cis-polybutadiene and butadiene-styrene random copolymers were attempted in THF at $0^{\circ} \mathrm{C}$ using TIDB. The reaction conditions and results are summarized in Table IV. The hydroxylated polymers obtained by oxidation after the hydroboration of polybutadiene were not optically active. The results agree with the authors' expectation that the asymmetric carbon atoms induced in the polymer obtained by the hydroboration of polybutadiene are pseudo asymmetric.

In the case of hydroboration of butadienestyrene copolymer, the reaction is shown as follows

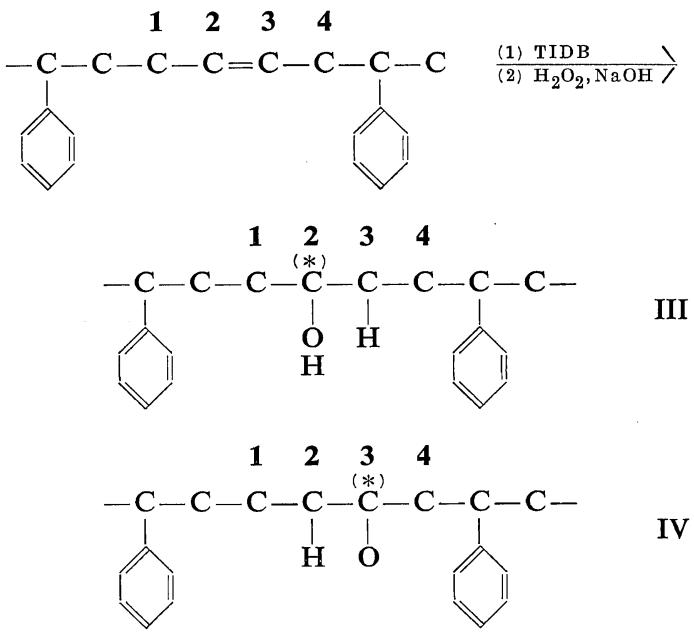

The hydroxylated polymer such as type III is optically inactive. On the contrary, the hydroxylated polymer such as type IV is optically active. It is thought that the statistical probability of formation of type III is equal to that of type IV in the asymmetric hydroboration. Thus the authors hoped that the obtained hydroxylated butadiene-styrene copolymer would be optically active. 


\section{Asymmetric Hydroboration of Diene Polymers}

Table IV. Asymmetric hydroboration a of polybutadiene, butadiene-styrene copolymer, and butadiene-acrylonitrile copolymer with triisopinocampheyldiborane ${ }^{b}$

\begin{tabular}{|c|c|c|c|c|c|c|}
\hline \multirow[b]{2}{*}{$\begin{array}{l}\text { Run } \\
\text { no. }\end{array}$} & \multicolumn{3}{|c|}{ Diene polymers } & \multicolumn{3}{|c|}{ Hydroxylated polymers } \\
\hline & Name & $\begin{array}{l}\text { Butadiene } \\
\text { unit content, } \\
\text { mol } \%\end{array}$ & {$[\eta]^{\mathrm{c}}$} & {$[\eta]^{\mathrm{c}}$} & $\begin{array}{c}-\mathrm{OH}^{\mathrm{d}} \\
\text { content, } \%\end{array}$ & {$[\alpha]_{D^{e}}$} \\
\hline 20 & Polybutadiene & 100 & 2.70 & 0.64 & 82.3 & 0 \\
\hline 21 & & 85 & 1.03 & 0.89 & 66.4 & 0 \\
\hline 22 & $\begin{array}{l}\text { Butadiene- } \\
\text { styrene copolymer }\end{array}$ & 85 & 1.03 & 0.70 & 86.0 & 0 \\
\hline 23 & & 68 & 1.54 & 0.63 & 40.9 & 0 \\
\hline 24 & & 68 & 1.54 & 0.72 & 36.8 & 0 \\
\hline 25 & & 25 & 0.54 & 0.36 & 62.4 & 0 \\
\hline 26 & & 25 & 0.54 & 0.42 & 87.6 & 0 \\
\hline $27^{f}$ & $\begin{array}{l}\text { Alternating } \\
\text { butadiene-- } \\
\text { acrylonitrile }\end{array}$ & 51 & 1.04 & 0.182 & 65.0 & +0.5 \\
\hline $28 \mathrm{~g}$ & & 51 & 1.04 & 0.588 & 71.1 & +0.8 \\
\hline $29^{f}$ & $\begin{array}{l}\text { Butadiene-- } \\
\text { acrylonitrile }\end{array}$ & 76 & 1.65 & 0.501 & 80.5 & 0 \\
\hline
\end{tabular}

a Asymmetric hydroboration was carried out at $0^{\circ} \mathrm{C}$ in THF. The molar ratio of triisopinocampheyldiborane(TIDE)/butadine unit $=1.0$.

b $\alpha$-pinene $[\alpha]+26.6^{\circ}$.

c Measured in THF at $30^{\circ} \mathrm{C}$.

d Calculated from analytical value $(\mathrm{C} \%)$. These values were calculated as $\frac{\text { hydroxylated } \mathrm{C}=\mathrm{C}}{\text { original } \mathrm{C}=\mathrm{C}} \times 100$.

- Measured in THF at $25^{\circ} \mathrm{C}(C=1.0, l=1.0)$.

f The hydroboration was carried out for $5 \mathrm{~min}$.

$\mathrm{g}$ The hydroboration was carried out for $5 \mathrm{~min}$. The molar ratio of triisopinocampheyldiborane(TIDE)/ butadiene unit $=0.5$.

h Obtained by free radical copolymerization.

The hydroxylated polymers obtained by oxidation after the asymmetric hydroboration of butadiene-styrene copolymers were also optically inactive although the authors expected that the hydroxylated polymers would be optically active as the symmetric structure was destroyed due to the styrene unit of the copolymers. ${ }^{12}$

The copolymer having alternative structure (styrene-butadiene-styrene) is the most effectively hydroborated one for showing optical activity. However, the values of $F_{\mathrm{St}-\mathrm{Bu}-\mathrm{St}}$ (probability of styrene-butadiene-styrene unit arrangement in main chain) of the used butadiene - styrene copolymers were $0.04-0.09$. Thus it is thought that the rotation of polarized light of hydroxylated copolymers cannot be observed as the contents of "true" asymmetric carbon atoms are very small.

Asymmetric Hydroboration of Butadiene-Acrylonitrile Copolymers

The asymmetric hydroboration of butadiene- acrylonitrile alternating and random copolymers was carried out in THF at $0^{\circ} \mathrm{C}$ using TIDB. The reaction conditions and results are summarized in Table IV.

The infrared spectrum of the hydroxylated copolymer is shown in Figure 4. The absorption band at $2237 \mathrm{~cm}^{-1}$ due to the $-\mathrm{C} \equiv \mathrm{N}$ group and that due to the carbon-carbon double bond was decreased. The absorption band at 3300 $\mathrm{cm}^{-1}$ due to the hydroxyl group was observed and those at $1720 \mathrm{~cm}^{-1}$ and $1650 \mathrm{~cm}^{-1}$ were also newly induced. The result of infrared spectrum suggested that the hydroxylation of carboncarbon double bonds occurred and a part of $-\mathrm{C} \equiv \mathrm{N}$ group converted to $-\mathrm{C}=\mathrm{N}-\mathrm{OH}$.

The hydroxylated butadiene-acrylonitrile alternating copolymer had positive optically rotation as shown in Table IV and the optical rotatory dispersion curve is shown in Figure 2. On the other hand, the hydroxylated butadiene-acrylonitrile random copolymer was not optically 


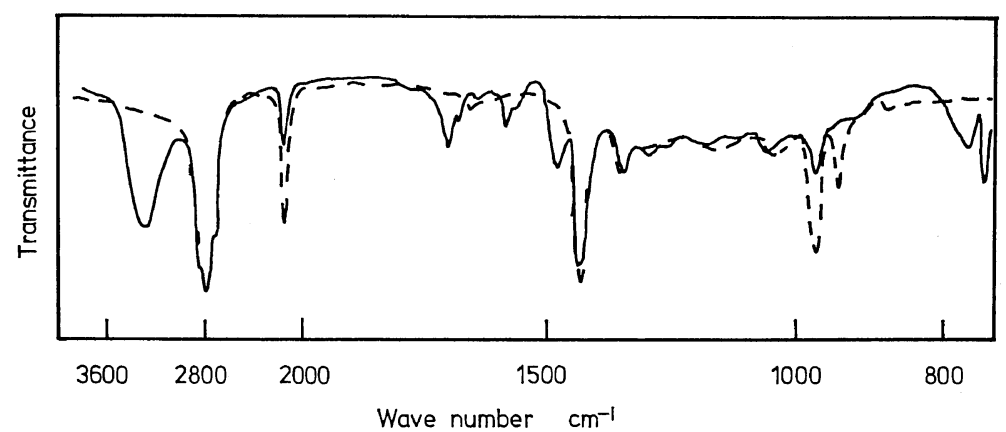

Figure 4. Infrared spectra of alternating butadiene-acrylonitrile copolymer (----) and its hydroxylated polymer (-).

active.

As described in the hydroboration of butadiene -styrene random copolymer, the fact that the hydroxylated butadiene-acrylonitrile alternating copolymer having the $F_{\mathrm{AN}-\mathrm{Bu}-\mathrm{AN}}$ high value (0.46) was optically active was also caused by the high concentration of "true" asymmetric carbon atoms. On the contrary, the hydroxylated butadiene-acrylonitrile random copolymer does not have a high concentration of "true" asymmetric carbon atoms and does not show the optical rotation because the $F_{\mathrm{AN}-\mathrm{Bu}-\mathrm{AN}}$ value of the butadiene-acrylonitrile copolymer is small (0.16).

Thus it is evident that the high value of probability of the comonomer-butadiene-comonomer unit arrangement in diene copolymer is essential for the formation of optically active polymer by the hydroboration.

It is confirmed from the results in this work that the asymmetric induction of two position

$$
\begin{array}{cc}
\mathrm{CH}_{3} & \mathrm{H} \\
\mathrm{I}_{3} & 1^{*} \\
\left(-\mathrm{C}^{*}-\right.\text { and } & \left.-\mathrm{C}^{*}-\right) \\
\mathrm{H} & \mathrm{O} H
\end{array}
$$

hydroboration of diene polymers with TIDB.

Acknowledgment. The authors would like to express their grateful acknowledgment to Dr.
Junji Furukawa (Kyoto University) for a present of butadiene-acrylonitrile alternating copolymer.

\section{REFERENCES}

1. H. C. Brown and G. Zweifel, J. Amer. Chem. Soc., 83, 486 (1961).

2. H. C. Brown, N. R. Ayyanger, and G. Zweifel, J. Amer. Chem. Soc., 86, 397 (1964).

3. H. Ikeda, A. Kogure, K. Shiina, and Y. Minoura, Kogyo Kagaku Zasshi (J. Chem. Soc., Japan, Chem. Ind. Sect.) 68, 1103 (1965).

4. I. Heilbron, et al., "Dictionary of Organic Compounds," Eyre and Spottiswoode Ltd., London, 19.65, p. 2756.

5. J. Furukawa, Y. Iseda, K. Haga, and N. Kataoka, J. Polym. Sci., Part B, 747 (1969).

6. H. C. Brown, G. Zweifel, and K. Nagase, $J$. Amer. Chem. Soc., 84, 183 (1962).

7. H. C. Brown, N. R. Ayyanger, and G. Zweifel, J. Amer. Chem. Soc., 86, 1071 (1964).

8. F. J. Welch, J. Polym. Sci., 61, 243 (1962).

9. R. L. Hansen and R. R. Haman, J. Phys. Chem., 67, 2868 (1963).

10. P. G. Allies and P. B. Brindley, J. Chem. Soc., (B), 1126 (1969).

11. H. C. Brown, N. R. Ayyanger, and G. Zweifel, J. Amer. Chem. Soc., 84, 4341 (1962), 84, 4342 (1962).

12. H. L. Frish, C. Schuerch, and M. Szwarc, $J$. Polym. Sci., 11, 559 (1953). 